\section{Should patients with inflammatory bowel disease smoke?}

An observation that fewer people with ulcerative colitis smoked cigarettes than would be expected ${ }^{1}$ has been confirmed by further studies. ${ }^{2-4}$ The relevance of this finding is at present not clear, ${ }^{5}$ but it has been suggested that smoking may protect against ulcerative colitis. The reports received widespread publicity, and we are often asked by patients with the disease for advice on smoking. We therefore studied smoking habits in patients with inflammatory bowel disease to ascertain whether smoking is associated with less severe disease.

\section{Patients, methods, and results}

A total of 252 consecutive outpatients with inflammatory bowel disease were interviewed and their case notes reviewed. Details were obtained of smoking habit, frequency of relapse, symptoms in remission and relapse, extent of disease, complications, and the numbers of admissions to hospital and of operations. The means of the three most recent full blood cell counts, white cell counts, erythrocyte sedimentation rates, albumin concentrations, and platelet counts were recorded. Patients were subdivided into three groups on conventional clinical grounds: 102 patients had ulcerative colitis, 96 Crohn's colitis, and 54 Crohn's disease of the small bowel. Patients with Crohn's disease in both the small bowel and the colon were included in the third group. Analysis of 172 variables for each patient was carried out with an ICL 2970 computer, using the statistical package for the social sciences (SPSS). The $\chi^{2}$ test, with Yates's correction factor when appropriate, was used for all cross tabulation of coded variables. Continuous variables were analysed with a two tailed Student's $t$ test. Probability values of less than 5\% were considered to be significant.

The proportion of cigarette smokers was smaller among patients with ulcerative colitis (eight $(8 \%)$ ) than among those with Crohn's colitis (24 $(25 \%) ; \mathrm{p}<0.02)$ or with small bowel Crohn's disease $(28(52 \%) ; \mathrm{p}<0.0001)$ the difference in the proportion of smokers between patients with Crohn's colitis and small bowel Crohn's disease was also significant $(p<0.02)$. Thirty three patients with ulcerative colitis $(32 \%), 29$ with Crohn's colitis $(30 \%)$ and seven with small bowel Crohn's disease (13\%) were ex-smokers. The groups were well matched for age, sex, social class, and duration of disease. The table shows clinical details of patients within groups according to current smoking habits. Smokers with Crohn's colitis tended to have relapses more often $(\mathrm{p}<0.028)$ and more severe pain $(\mathrm{p}<0.007)$ than non-smokers. Smokers with small bowel Crohn's disease tended to have more frequent bowel movements $(p<0.05)$, more admissions to hospital $(p<0.05)$, more operation $(p<0.04)$, and higher white cell counts $(p<0.001)$. There were relatively few smokers with ulcerative colitis which made comparison largely irrelevant in this group. Of the total of 252 patients, 13 claimed to have continuous symptoms, nine of whom were current smokers, whereas of 49 patients who had on average less than one relapse a year, only 11 smoked $(p<0.004)$

\section{Comment}

This study confirms the low prevalence of smoking among patients with ulcerative colitis. Smokers therefore appear to have a reduced risk of developing the disease, and possibly smoking is in some way protective. We think, however, that a more attractive hypothesis is that smoking in some way influences the pathological appearances, possibly by an effect on the immune system, leading to features of Crohn's disease rather than ulcerative colitis.

It is difficult to assess the course of disease in a retrospective study, but smokers tended to do worse on most counts in each group of patients studied. Two explanations are possible: either smoking has a direct effect on the disease or patients who have more severe symptoms find psychological relief by continuing smoking. In either event, our findings together with the known health hazard of smoking lead us to conclude that, for the present, patients with inflammatory bowel disease should be advised to stop smoking.

${ }^{1}$ Harries AD, Baird A, Rhodes J. Non-smoking : a feature of ulcerative colitis. Br Med f 1982;284:706.

${ }^{2}$ Bureš J, Fixa B, Komárková O, Fingerland A. Non-smoking: a feature of ulcerative colitis. $B r$ Med f 1982;285:440.

${ }^{3} \mathrm{Jick} \mathrm{H}$, Walker AM. Cigarette smoking and ulcerative colitis. $N$ Engl $\mathrm{f}$ Med $1983 ; 308: 261-3$

4 Logan R, Edmund M, Langman MJS. Is non-smoking associated with ulcerative colitis? Gut 1983;24:A499.

${ }^{5}$ Bailas JC. Cigarettes, ulcerative colitis and inferences from uncontrolled data. N Engl f Med 1983;308:275-7.

(Accepted 18 October 1983)

Southampton General Hospital, Southampton SO9 4XY

GREG HOLDSTOCK, DM, MRCP, senior registrar

D SAVAGE, medical student

M HARMAN, BSC, MBCs, faculty computer programmer

RALPH WRIGHT, DPHIL, FRCP, professor of medicine

Correspondence to: Dr G Holdstock.

\section{Liver damage from verapamil}

Verapamil hydrochloride, a derivative of papaverine, is a calcium channel blocking drug used to treat angina pectoris, supraventricular tachycardia, subaortic stenosis, and hypertension. Several recent reports have suggested that verapamil may induce liver injury. ${ }^{1-4}$ We report a case of idiosyncratic hepatic injury caused by verapamil.

\section{Case report}

The patient was a 47 year old man with an unremarkable medical and family history. One week before admission to hospital he had complained of diffuse abdominal pain, fever $\left(38^{\circ} \mathrm{C}\right)$, arthralgias, headache, and vomiting followed by dark urine and jaundice. Hepatitis was diagnosed. Treatment for angina pectoris with dipyridamole $220 \mathrm{mg}$ daily and verapamil $120 \mathrm{mg}$ daily had been started three months and two weeks previously, respectively. On clinical examination on 3 February he had jaundice and diffuse abdominal pain especially in the right upper quadrant, with the liver palpable $8 \mathrm{~cm}$ below the costal margin. The spleen was not palpable.

Laboratory findings showed serum bilirubin concentration $128 \mu \mathrm{mol} / \mathrm{l}$ $(7.5 \mathrm{mg} / 100 \mathrm{ml}$ ) (normal range $1 \cdot 7-17 \mu \mathrm{mol} / 1(0 \cdot 1-1.0 \mathrm{mg} / 100 \mathrm{ml})$ ); serum

Comparison of clinical course of disease in each diagnostic group according to current smoking habit

\begin{tabular}{|c|c|c|c|c|c|c|}
\hline & \multicolumn{2}{|c|}{ Ulcerative colitis } & \multicolumn{2}{|c|}{ Crohn's colitis } & \multicolumn{2}{|c|}{ Small bowel Crohn's disease } \\
\hline & Non-smokers & Smokers & Non-smokers & Smokers & Non-smokers & Smokers \\
\hline No of patients & 94 & 8 & 71 & 24 & 26 & 28 \\
\hline Mean (SD) No of relapses in past year & $1 \cdot 9(2 \cdot 6)$ & $2 \cdot 3(0.9)$ & \multicolumn{2}{|c|}{$\mathrm{p}<0.03$} & $1.9(3.5)$ & $2 \cdot 96(3.5)$ \\
\hline Mean (SD) No of relapses/year & $1 \cdot 9(2 \cdot 6)$ & $2 \cdot 2(1 \cdot 1)$ & $2 \cdot 1(2 \cdot 3)$ & $2.9(1.9)$ & $3.5(5)$ & $4 \cdot 4(5 \cdot 4)$ \\
\hline Mean (SD) severity of pain during relapse* & \multicolumn{2}{|c|}{$5.5(2.3) \mathrm{p}<0.009^{9.0(18)}$} & \multicolumn{2}{|c|}{${ }^{5.3(2.3)} \mathrm{p}<0.007^{7.2(2.3)}$} & $6 \cdot 8(2 \cdot 5)$ & $7 \cdot 0(2 \cdot 3)$ \\
\hline Mean (SD) bowel frequency/day during relapse & $7 \cdot 2(5 \cdot 4)$ & $7 \cdot 0(7 \cdot 8)$ & $6 \cdot 1(5 \cdot 1)$ & $7 \cdot 3(6 \cdot 4)$ & \multirow{2}{*}{\multicolumn{2}{|c|}{$1.0(0.9) \begin{array}{l}\mathrm{p}<0.05 \\
\mathrm{p}<0.05\end{array} 1.9(1.8)$}} \\
\hline Mean (SD) No of hospital admissions/patient & $0.6(0.9)$ & $0.6(0.8)$ & $0 \cdot 76(8)$ & $0.98(1)$ & & \\
\hline No undergoing surgery & 4 & & 7 & 2 & \multicolumn{2}{|c|}{$\mathrm{p}<0.04$} \\
\hline Mean (SD) white cell count $\left(\times 10^{\circ} / 1\right)$ & $7 \cdot 9(2 \cdot 2)$ & $7 \cdot 8(2 \cdot 8)$ & $9 \cdot 7(11 \cdot 3)$ & $9 \cdot 7(2 \cdot 8)$ & \multicolumn{2}{|c|}{ 1.9) $\mathrm{p}<0.001^{9.7(2.2)}$} \\
\hline Mean (SD) erythrocyte sedimentation rate ( $\mathrm{mm}$ in first $\mathrm{h}$ ) & $16(15)$ & $13(21)$ & $20(8)$ & $24(11)$ & $18(15)$ & $27(21)$ \\
\hline
\end{tabular}

* Measured on linear analogue scale of 0-10. 